\title{
PHẪU THUẬT NộI SOI TOÀN Bộ CẮT TÚI THỪA NHĨ PHẢI
}

Đặng Quang Huy ${ }^{*}$, Nguyễn Minh Ngọc ${ }^{*}$, Trần Tiến Mạnh*

\section{TÓM TẮT}

Túi thừa nhĩ phải là bệnh lý bẩm sinh hiếm gặp với hơn 30 ca bệnh được công bố. Phẫu thuật là phương pháp điều trị chủ yếu, được chỉ định khi người bệnh có triệu chứng hoặc có dấu hiệu chèn ép các cấu trúc tim phải. Trong báo cáo này, chúng tôi công bố trường hợp đầu tiên áp dụng phương pháp phẫu thuật nội soi toàn bộ, không robot hỗ trợ cắt túi thừa nhĩ phải trong điều kiện tim đập.

Tù khóa: túi thùa nhĩ phải, phẫu thuật nội soi toàn bộ

\section{SUMMARY}

Right atrial diverticulum was a rare congenital heart defect, with only about 30 cases had been reported. Surgical was the main method of treatment, and was indicated when the patients had signs of right heart compression. In this case report we present the first case of right atrial diverticulum treated with non-robotic, beating hearrt total endoscopic surgery for complete resection of the diverticulum.

Keywords: right atrial diverticulum, total endoscopic surgery

\section{I. ĐẠTT VẤN ĐỀ}

Túi thừa nhĩ phải là bệnh lý bẩm sinh hiếm gặp với hơn 30 ca bệnh được báo cáo riêng lẻ. Phẫu thuật là phương pháp điều trị chủ yếu ngay cả khi người bệnh không có triệu chứng nhằm phòng ngừa biến chứng đột tử hoặc huyết khối gây tắc mạch phổi. Mặc dù vậy, tất cả các báo cáo đều là phẫu thuật qua đường mổ kinh điển - cưa toàn bộ xương ức. Trong báo cáo này, chúng tôi mô tả một trường hợp túi thừa nhĩ phải được phẫu thuật thành công bằng phương pháp phẫu thuật nội soi toàn bộ, không robot hỗ trợ, trong điều kiện tim đập.

\section{CA LÂM SÀNG}

Bệnh nhân nam 43 tuổi vào viện với triệu chứng đau tức ngực trái và khó thở khi gắng sức mới xuất hiện trong thời gian 3 tháng. X-quang ngực thẳng cho hình ảnh bóng tim to. Siêu âm tim qua thành ngực xác định một túi thừa với kích thước: $68,3 \mathrm{~mm} \times 30,8 \mathrm{~mm}$ xuất phát từ thành tự do nhĩ phải. Túi thừa thông thương với nhĩ phải qua cổ túi có đường kính: 20,5mm (hình $1 \mathrm{~A}$ ). Có dấu hiệu đè ép vòng van ba lá và thất phải, van ba lá hở nhẹ. Cộng hưởng từ tim xác định chẩn đoán túi thừa nhĩ phải với kích thước $81 \times 52 \mathrm{~mm}$, túi thừa phát triển qua rãnh nhĩ thất về phía mặt trước thất phải, gây đè ép rõ vòng van ba lá và thất phải trong thì tâm thu (hình $1 \mathrm{~B}$ ). Không có huyết khối trong lòng túi thừa. Điện tâm đồ không phát hiện rối loạn nhịp nhĩ.

Bệnh nhân được lên kết hoạch cắt túi thừa bằng phương pháp nội soi toàn bộ, không robot hỗ trợ, trong điều kiện tim đập.

Bệnh nhân được thiết lập tuần hoàn ngoài cơ thể ngoại vi với ống thông động mạch được đặt gián tiếp qua đoạn mạch Dacron số 8 (UniGraft@, Aesculap AG, Tuttlingen, Germany). Ông thông tĩnh mạch chủ trên và dưới được đặt qua tĩnh mạch cảnh trong và tĩnh mạch đùi phải theo phương pháp Seldinger. Thiết lập 3 đường vào cho dụng cụ, bao gồm: 01 cổng $12 \mathrm{~mm}$ tại khoang liên sườn (KLS) VI đường nách trước cho tay làm việc chính; 01 trocar $5 \mathrm{~mm}$ tại KLS VI, đường nách giữa cho camera; 01 trocar $5 \mathrm{~mm}$ tại KLS III, đường nách giữa cho tay làm việc phụ.

\footnotetext{
* Bệnh viện tim Hà Nội

Người chịu trách nhiệm khoa họ: BS Đặng Quang Huy

Ngày nhận bài: 01/11/2019 - Ngày Cho Phép Đăng: 20/12/2019

Phản Biện Khoa học: PGS.TS. Đặng Ngọc Hùng GS.TS. Lê Ngoc Thành
} 


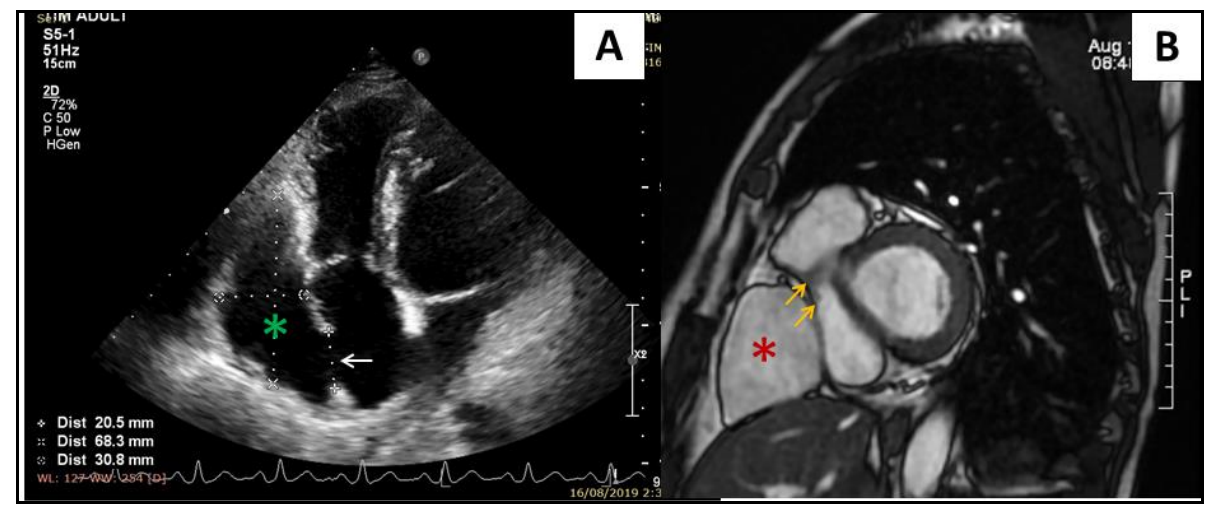

Hình 1: Hình ảnh túi thù̀a nhĩ phải trên siêu âm tim qua thành ngục và cộng hưởng tù tim.

$\mathbf{A}$, hình ảnh từ mặt cắt bốn buồng qua mỏm, túi thừa (dấu hoa thị mầu xanh dương) xuất phát từ thành tự do nhĩ phải; nhĩ phải và túi thừa thông thương với nhau qua cổ túi thừa (mũi tên mầu trắng); $\mathbf{B}$, mặt cắt đứng dọc trên phim cộng hưởng từ tim, túi thừa (dấu hoa thị mầu đỏ) nằm trước vòng van ba lá và thất phải, đè ép các cấu trúc này (mũi tên mầu vàng).

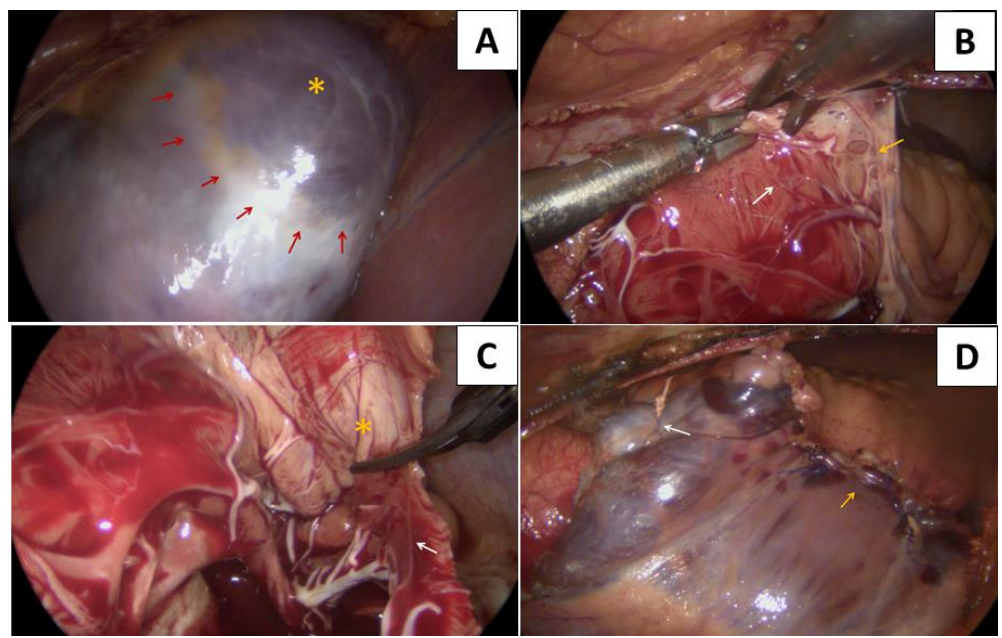

Hình 2: Hình ảnh tổn thương trong mổ và quá trình phẫu thuật

A, Túi thừa (dấu hoa thị mầu vàng) xuất phát từ thành tự do nhĩ phải, phát triển qua rãnh nhĩ thất về mặt trước thất phải. Ranh giới giữa túi thừa và nhĩ phải (tương ứng với cổ túi ở mặt trong) khá rõ khi nhìn từ mặt ngoài (các dấu mũi tên mầu đỏ); $\mathbf{B}$, Sự khác biệt giữa thành túi thừa (mũi tên mầu vàng) và thành nhĩ phải (mũi tên mầu trắng); $\mathbf{C}$, Cắt bỏ túi thừa (dấu hoa thị mầu vàng) dọc theo phần ranh giới giữa túi thừa và nhĩ phải (mũi tên mầu trắng); $\mathbf{D}$, Đường khâu nhĩ phải sau khi đã được cắt bỏ túi thừa (mũi tên mầu vàng) và tiểu nhĩ phải được thắt để giảm thể tích (mũi tên mầu trắng).

Sau khi mở màng tim, túi thừa được xác định xuất phát từ thành tự do nhĩ phải phát triển qua rãnh nhĩ thất và nằm ở mặt trước thất phải. Ranh giới giữa nhĩ phải và túi thừa khá rõ. Tiểu nhĩ phải giãn lớn hơn so với bình thường (hình 2A). Sau khi thắt TMC trên, nhĩ phải được mở dọc theo ranh giới giữa nhĩ phải và túi thừa. Thành túi thừa mỏng, có mầu trắng và các bè cơ không quan sát thấy mà bị thay thế bằng các dải xơ. Về đại thể quan sát thấy ranh giới rõ giữa thành túi thừa và thành nhĩ phải (hình $2 \mathrm{~B}$ ). Thành túi thừa hướng về phía rãnh nhĩ thất và mặt trước thất phải, dính chặt vào các cấu trúc này. Chúng tôi quyết định cắt bỏ tối đa thành túi thừa, trong khi vẫn giữ lại phần túi thừa ở vị trí rãnh nhĩ thất để tránh nguy cơ tổn thương động mạch vành phải trong quá trình gỡ dính (hình 2C). Cổ túi thừa (thành nhĩ phải) còn lại đượng khâu đóng trực tiếp 2 lớp. Tiểu nhĩ phải được thắt buộc 2 lớp để loại trừ phần giãn (hình $2 \mathrm{D})$. 
Thời gian thời gian chạy máy tuần hoàn ngoài cơ thể là 76 phút và thời gian phẫu thuật là 210 phút. Về hồi sức rút ống nội khí quản sau 4h, không có thuốc trợ tim. Người bệnh hồi phục nhanh và ra viện sau 05 ngày không còn triệu chứng đau ngực. Kết quả chụp cộng hưởng từ tim sau mổ cho thấy túi thừa đã được loại bỏ hoàn toàn, vòng van ba lá và thất phải không còn bị chèn ép, chức năng thất phải trở về giá trị bình thường. Kết quả giải phẫu bệnh cho thấy thành túi thừa cấu trúc bởi 2 lớp: nội tâm mạc và tổ chức liên kết xơ không có cơ trơn. Người bệnh và gia đình hài lòng với kết quả phẫu thuật.

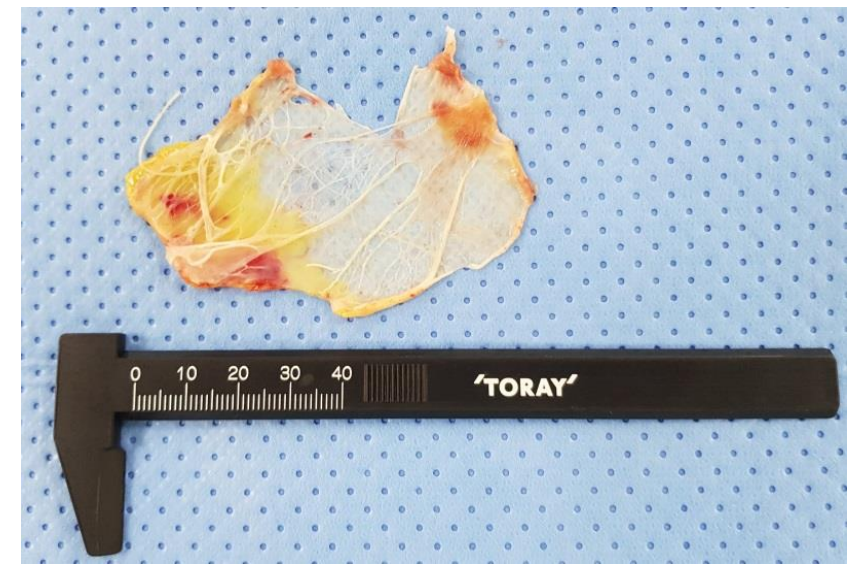

Hình 3: Thành túi thì̀a sau khi được cắt bỏ

\section{BÀN LUẬN}

Túi thừa nhĩ phải là bệnh bẩm sinh hiếm gặp với 32 báo cáo dưới dạng ca bệnh thuộc lĩnh vực phẫu thuật, chẩn đoán hình ảnh... Trong đó 6/32 bệnh nhân không có triệu chứng, được chẩn đoán tình cờ bằng các phương tiện chẩn đoán hình ảnh [1-4], chỉ định phẫu thuật ở những bệnh nhân này còn nhiều tranh cãi [2]. Cơ chể bệnh sinh của túi thừa nhĩ phải vẫn còn chưa rõ.

Ở bệnh nhân túi thừa nhĩ phải, cảm giác hồi hộp, đánh trống ngực do rối loạn nhịp nhĩ (rung nhĩ, cuồng nhĩ, nhịp nhanh trên thất, hội chứng WPW) là những triệu chứng thường gặp nhất [57]. Triệu chứng đau tức, khó chịu ở ngực gặp ở $5 / 32$ bệnh nhân [8-12]. Chèn ép vòng van ba lá và thất phải là dấu hiệu gặp ở những túi thừa lớn lan qua rãnh nhĩ thất tới mặt trước thất phải $[3,7$, 13]. Hầu hết tác giả thống nhất chỉ định mổ khi túi thừa có triệu chứng hoặc chèn ép các cấu trúc tim phải $[4,14]$. Bệnh nhân của chúng tôi có triệu chứng đau tức ngực trái và túi thừa chèn ép vòng van ba lá, thất phải; chức tâm thu thất phải giảm vì vậy chỉ định mổ là rõ ràng.

Trong 32 báo cáo được công bố, 21 trường hợp được phẫu thuật cắt túi thừa. Trong những báo cáo phẫu thuật này, tất cả các tác giả đều sử dụng đường tiếp cận truyền thống cưa toàn bộ xương ức $[7,15,16]$. Phẫu thuật tim đập được áp dụng ở $3 / 21$ trường hợp $[3,15,17]$. Ca bệnh của chúng tôi là trường hợp đầu tiên sử dụng phương pháp phẫu thuật nội soi toàn bộ, không robot hỗ trợ cắt túi thừa trong điều kiện tim đập.

Với những túi thừa sát vòng $\mathrm{VBL}$, túi thừa thường phát triển qua rãnh nhĩ thât phải và hướng về mặt trước TP. Trong trường hợp này, thành sau túi thừa thường dính chặt vào rãnh nhĩ thất và có thể cả mặt trước thất phải khiến cho việc phẫu tích và cắt bỏ toàn bộ thành túi thừa mà không làm tổn thương ĐMV phải hoặc TP là rất khó [7, 17]. Iwata cùng cộng sự đã quyết định để lại phần túi thừa nằm trên rãnh nhĩ thất để tránh nguy cơ tổn thương động mạch vành phải khi phẩu tích [7]. Ở bệnh nhân của chúng tôi, việc phẫu tích tách rời túi thừa khỏi mặt trước thất phải và rãnh nhĩ thất là rất khó; vì lý do đó, chúng tôi cũng quyết định để lại phần túi thừa này.

Trong thực hành lâm sàng, việc phân biệt giữa bệnh giãn nhĩ phải và túi thừa nhĩ phải là khó khăn trong những trường hợp cổ túi thừa rộng. Trong trường hợp đó, tiêu chuẩn phân biệt dựa vào kêt quả mô bệnh học. Trong giãn nhĩ phải, phần thành nhĩ vẫn bao gồm đầy đủ 3 lớp, trong đó có lớp cơ trơn. Trong khi đó, hầu hết tác giả ghi nhận thành túi thừa được cấu tạo bởi tổ chức liên kết xơ và lớp nội mạc, lớp cơ trơn bị thoái triển không còn nữa hoặc còn rât ít $[2,3,7]$. 
Đó là lý do khiến túi thừa tăng dần kích thước và có nguy cơ vỡ. Bệnh nhân của chúng tôi có hình ảnh đại thể rõ ràng của thành mỏng, tổ chức xơ thay thế lớp cơ trơn. Mô bệnh học xác định tình trạng không còn lớp cơ trơn trong thành túi thừa.

\section{KẾT LUẬN}

Túi thừa nhĩ phải là bệnh lý bẩm sinh hiếm gặp. Phẫu thuật nội soi toàn bộ cắt túi thừa trong điều kiện tim đập là phương pháp an toàn và hiệu quả.

\section{TÀI LIỆ THAM KHẢO}

1. Funabashi N, Sekine T, Komuro I. Idiopathic diverticulum-type enlargement of the right atrium demonstrated by multislice computed tomography. Heart (British Cardiac Society). 2006 Aug;92(8):1144.

2. Agematsu K, Okamura $\mathrm{T}$, Ishihara $\mathrm{K}$, Kurosawa H. Remarkable giant right atrial diverticulum in asymptomatic patient. Interactive cardiovascular and thoracic surgery. 2009 Jun;8(6):705-7.

3. Borgohain S, Malik L, Prasad S, Gupta A, Grover V, Gupta VK. Case of single right atrial diverticulum and review of etiology and management. Asian cardiovascular \& thoracic annals. 2013 Oct;21(5):592-5.

4. Sato Y, Satokawa H, Yamamoto A, Yokoyama H, Maehara K. Giant right atrial diverticulum with thrombus formation. Asian cardiovascular \& thoracic annals. 2015 Mar;23(3):314-6.

5. Gaita F, Haissaguerre M, Scaglione M, Jais P, Riccardi R, Lamberti F, et al. Catheter ablation in a patient with a congenital giant right atrial diverticulum presented as Wolff-ParkinsonWhite syndrome. Pacing and clinical electrophysiology : PACE. 1999 Feb;22(2):382-5.

6. Hasdemir C, Gurgun C, Yavuzgil O, Yuksel A, Beckman KJ. Giant right atrial diverticulum associated with Wolff-ParkinsonWhite syndrome. Journal of cardiovascular electrophysiology. 2006 Apr;17(4):443.

7. Iwata S, Nomura M, Ozaki $M$. Intraoperative Transesophageal Echocardiographic Findings in Surgical Resection of a Giant Right Atrial Diverticulum That Severely Compressed the Right Ventricle. Journal of cardiothoracic and vascular anesthesia. 2018 Apr;32(2):796-800.

8. Chen X, Guo X, Ni Y, Yu J, Cha Y,
Yang Y. Giant right atrial diverticulum in an adult. Journal of cardiac surgery. 2010 JanFeb;25(1):40-2.

9. Kurian KC, Nguyen M, Wilke N. Images in cardiology: right atrial diverticulum--a rare cause of atrial fibrillation. Clinical cardiology. 2007 Dec;30(12):631.

10. Morrow AG, Behrendt DM. Congenital aneurysm (diverticulum) of the right atrium. Clinical manifestations and results of operative treatment. Circulation. 1968 Jul;38(1):124-8.

11. da Silva Castro A, Ferreira N, Ferraz R, Bettencourt N, Mota JC, Gama Ribeiro V. A rare case of congenital aneurysm of the right atrium. Revista portuguesa de cardiologia : orgao oficial da Sociedade Portuguesa de Cardiologia = Portuguese journal of cardiology : an official journal of the Portuguese Society of Cardiology. 2014 Sep;33(9):571-2.

12. Morishita Y, Kawashima S, Shimokawa S, Taira A, Kawagoe H, Nakamura K. Multiple diverticula of the right atrium. American heart journal. 1990 Nov;120(5):1225-7.

13. Shah K, Walsh K. Giant right atrial diverticulum: an unusual cause of WolffParkinson-White syndrome. $\mathrm{Br}$ Heart J. 1992;68(1):58-9.

14. Binder TM, Rosenhek $R$, Frank $H$, Gwechenberger M, Maurer G, Baumgartner H. Congenital malformations of the right atrium and the coronary sinus: an analysis based on 103 cases reported in the literature and two additional cases. Chest. 2000 Jun;117(6):1740-8.

15. Kobza R, Oechslin E, Pretre R, Kurz DJ, Jenni R. Enlargement of the right atrium-diverticulum or aneurysm? European journal of echocardiography : the journal of the Working Group on Echocardiography of the European Society of Cardiology. 2003 Sep;4(3):223-5.

16. Streb W, Jarski P, Przybylski R, Glowacki J, Zembala M, Kalarus Z, et al. [Right atrial diverticulum in an adult patient]. Kardiologia polska. 2007 Sep;65(9):1090-3.

17. Campbell RM, Parks WJ, Crawford FA, Gillette PC. Right atrial diverticulum presenting as Wolff-Parkinson-White syndrome. Pacing and clinical electrophysiology : PACE. 1992 Aug;15(8):1101-4. 